(6)

\title{
An observation on inappropriate probiotic subgroup classifications in the meta-analysis by Lau and Chamberlain
}

This article was published in the following Dove Press journal:

International Journal of General Medicine

30 September 2016

Number of times this article has been viewed

\section{Lynne V McFarland}

Department of Medicinal Chemistry, University of Washington, Seattle, WA, USA
Correspondence: Lynne V McFarland Department of Medicinal Chemistry, University of Washington, Seattle, WA 98195, USA

Email lvmcfarl@u.washington.edu

\section{Dear editor}

I read with great interest the systematic review of meta-analysis assessing probiotics for the prevention of Clostridium difficile-associated diarrhea (CDAD) published in the International Journal of General Medicine. ${ }^{1}$ These authors pooled 26 randomized controlled trials (RCTs) and concluded that Lactobacilli, mixtures, and Saccharomyces probiotics were effective in preventing CDAD. However, the meta-analysis by Lau and Chamberlain is flawed due to improper classification by the types of probiotics. It is important to recognize that the efficacy of probiotics for various diseases has been shown to be strain specific for each probiotic product, and thus the data should only be pooled for probiotics that are of the identical type. ${ }^{2,3}$ In their analysis of probiotic subgroups by various species, the authors have inappropriately merged different types of Lactobacilli into one subgroup "Lactobacilli" and different types of mixtures into one group classified as "Mix". The Lactobacilli subgroup actually contains RCTs using six different types of Lactobacilli: Lactobacilli rhamnosus GG (three RCTs), one mixture of three Lactobacilli strains (Lactobacilli acidophilus CL1285, Lactobacilli casei LBC80R, and L. rhamnosus CLR2) (three RCTs), L. acidophilus (one RCT), one mixture of three strains of L. rhamnosus (E/n, Oxy, and Pen) (one RCT), L. casei Shirota (one RCT), and Lactobacilli plantarum 299v (one RCT). The Mix subgroup contains RCTs of five different types of strains, and only two trials evaluated the same type of probiotic mixture (L. acidophilus and Bifidobacterium bifidum). Only the Saccharomyces subgroup correctly pooled seven RCTs using the same strain of probiotic (Saccharomyces boulardii CNCM I-745). When these subgroups are pooled appropriately, as shown in Figure 1, only three types of probiotics have efficacy for the primary prevention of CDAD: $S$. boulardii $(P=0.003)$ and two mixtures $(\mathrm{BioK}+$, a mixture of three Lactobacilli strains ${ }^{4}[P<0.001]$ and the mixture of $L$. acidophilus with B. bifidum $[P=0.002])$. L. rhamnosus $\mathrm{GG}$ did not significantly prevent $\mathrm{CDAD}(P=0.65)$, a finding that is not apparent in the meta-analysis presentation of Lau and Chamberlain. No other probiotic strains had a second confirmatory RCT, and hence it is inappropriate to pool these different strains together. Only by appropriately combining and pooling data using the same strain or strains of probiotics can practical clinical guidance be determined as to which specific probiotic strains can be used to prevent CDAD.

\section{Disclosure}

The author is on the Scientific Advisory Board of Biok + and a paid lecturer of Biocodex. The author reports no other conflicts of interest in this communication. 
Study

ID
$\operatorname{RR}(95 \% \mathrm{Cl})$

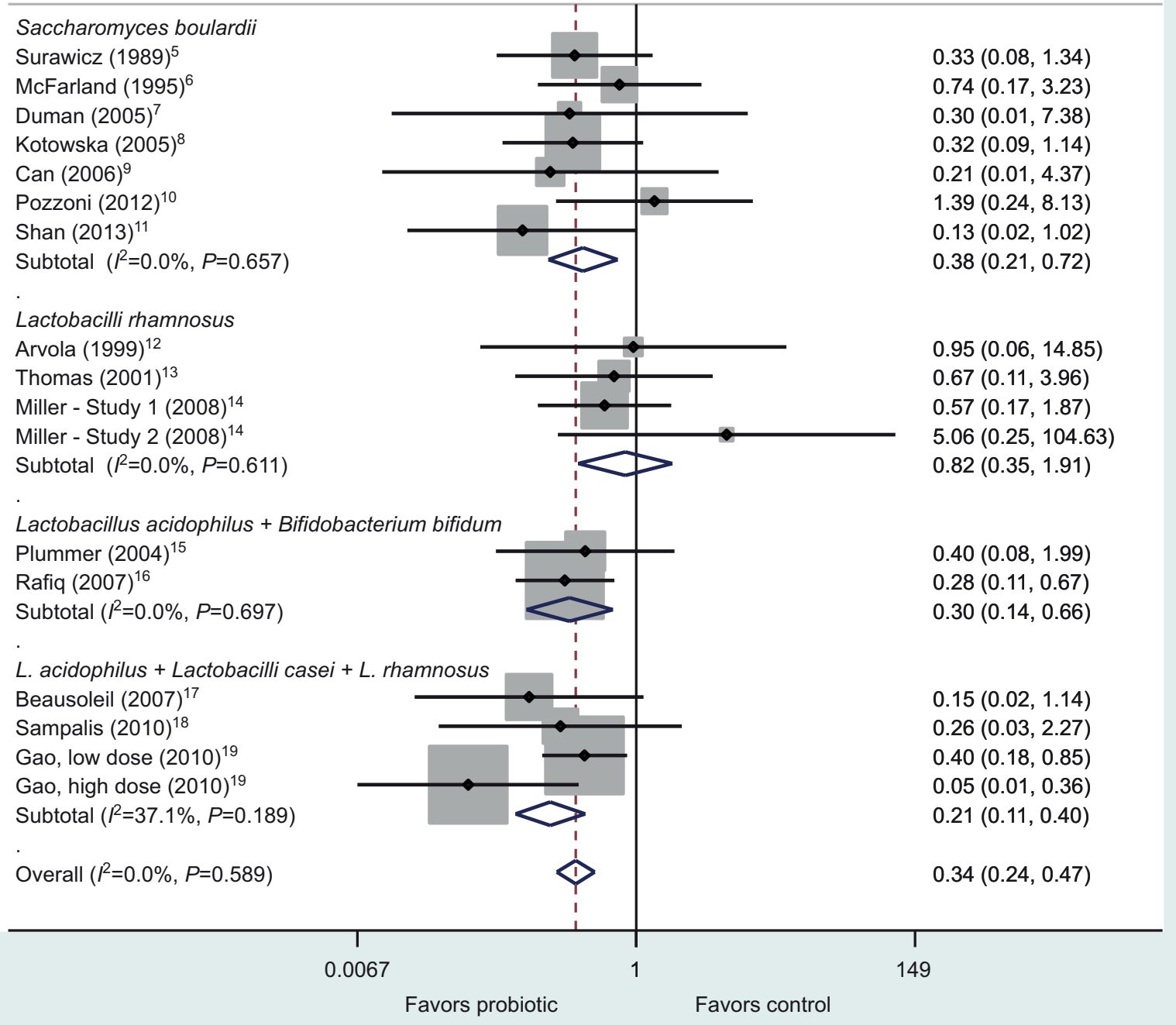

Figure I Forest plot of 15 randomized controlled trials by four probiotic subgroups for the primary prevention of Clostridium difficile disease. Adapted from Lau CS, Chamberlain RS. Probiotics are effective at preventing Clostridium difficile-associated diarrhea: a systematic review and meta-analysis. Int J Gen Med. 20I6;9:27-37.' Abbreviations: $\mathrm{RR}$, relative risk; $\mathrm{Cl}$, confidence interval.

\section{References}

1. Lau CS, Chamberlain RS. Probiotics are effective at preventing Clostridium difficile-associated diarrhea: a systematic review and metaanalysis. Int J Gen Med. 2016;9:27-37.

2. Hill C, Guarner F, Reid G, et al. Expert consensus document: the International Scientific Association for Probiotics and Prebiotics consensus statement on the scope and appropriate use of the term probiotic. Nat Rev Gastroenterol Hepatol. 2014;11(8):506-514.

3. McFarland LV. Importance of subgroup analysis in probiotic metaanalyses. Letter to the Editor. Br J Nutr. 2016;116:375-376.

4. Auclair J, Frappier M, Millette M. Lactobacillus acidophilus CL1285, L. casei LBC80R and L. rhamnosus CLR2 (Bio- $\mathrm{K}+$ ): characterization, manufacture, mechanisms of action and quality control of a specific probiotic combination for primary prevention of Clostridium difficile infections. CID. 2015;60(suppl 2):S135-S144.

5. Surawicz CM, Elmer GW, Speelman P, et al. Prevention of antibioticassociated diarrhea by Saccharomyces boulardii: a prospective study. Gastroenterology. 1989; 96:981-988.
6. McFarland LV, Surawicz CM, Greenberg RN, et al. Prevention of -lactam-associated diarrhea by Saccharomyces boulardii compared to placebo. Am J Gastroenterol. 1995;90:439-448.

7. Duman DG, Bor S, Ozütemiz O, et al. Efficacy and safety of Saccharomyces boulardii in prevention of antibiotic-associated diarrhoea due to Helicobacter pylori eradication. Eur J Gastroenterol Hepatol. 2005;17(12):1357-1361.

8. Kotowska M, Albrecht P, Szajewska H. Saccharomyces boulardii in the prevention of antibiotic-associated diarrhoea in children: a randomized double-blind placebo-controlled trial. Alimentary Pharmacology and Therapeutics. 2005;21(5):583-590.

9. Can M, Beirbellioglu BA, Avci IY, Beker CM, Pahsa A. Prophylactic Saccharomyces boulardii in the prevention of antibioticassociated diarrhea: a prospective study. Med Sci Monit. 2006;12(4): 119-122.

10. Pozzoni P, Riva A, Bellatorre AG, et al. Saccharomyces boulardii for the prevention of antibiotic-associated diarrhea in adult hospitalized patients: a single-center, randomized, double-blind, placebo-controlled trial. Am J Gastroenterol. 2012;107(6):922-931. 
11. Shan L, Hou P, Wang Z, et al. Prevention and treatment of diarrhea with Saccharomyces boulardii in children with acute lower respiratory tract infections. Beneficial Microbes. 2013;4(4):329-334.

12. Arvola T, Laiho K, Torkkeli S, et al. Prophylactic Lactobacillus GG reduces antibiotic-associated diarrhea in children with respiratory infections: a randomized study. Pediatrics. 1999;104(5):e64.

13. Thomas MR, Litin SC, Osmon DR, Corr AP, Weaver AL, Lohse CM. Lack of effect of Lactobacillus GG on antibiotic-associated diarrhea: a randomized, placebo-controlled trial. Mayo Clin Proc. 2001;76: 883-889.

14. Miller M, Florencio S, Eastmond J, Reynolds S. Results of 2 prospective randomized studies of Lactobacillus GG to prevent $C$. difficile infection in hospitalized adults receiving antibiotics. Abstract of the Interscience Conference on Antimicrobial Agents and Chemotherapy. 2008;48:578-579.

15. Plummer S, Weaver MA, Harris JC, Dee P, Hunter J. Clostridium difficile pilot study: effects of probiotic supplementation on the incidence of $C$. difficile diarrhoea. Int Microbiol. 2004;7:59-62.
16. Rafiq R. Prevention of Clostridium difficile (C. difficile) diarrhea with probiotic in hospitalized patients treated with antibiotics. Gastroenterol. 2007:132(4):187. Abstract S1167.

17. Beausoleil M, Fortier N, Guénette S, et al. Effect of a fermented milk combining Lactobacillus acidophilus C11285 and Lactobacillus casei in the prevention of antibiotic-associated diarrhea: a randomized, doubleblind, placebo-controlled trial. Can J Gastroenterology. 2007;21(11) $732-736$.

18. Sampalis J, Psaradellis E, Rampakakis E. Efficacy of BIO K+ CL1285 in the reduction of antibiotic-associated diarrhea - a placebo controlled double-blind randomized, multi-center study. Arch Med Sci. 2010;6(1): 56-64.

19. Gao XW, Mubasher M, Fang CY, Reifer C, Miller LE. Dose-response efficacy of a proprietary probiotic formula of Lactobacillus acidophilus CL1285 and Lactobacillus casei LBC80R for antibiotic-associated diarrhea and Clostridium difficile-associated diarrhea prophylaxis in adult patients. Am J Gastroenterol. 2010;105(7):1636-1641. 


\section{Authors' reply}

Christine SM Lau',2

Ronald S Chamberlain ${ }^{1-3}$

'Department of Surgery, Saint Barnabas Medical Center, Livingston, NJ, USA; ${ }^{2}$ Saint George's University School of Medicine, Grenada, West Indies; ${ }^{3}$ Department of Surgery, New Jersey Medical School, Rutgers University, Newark, NJ, USA

Correspondence: Ronald S Chamberlain

Department of Surgery, Saint Barnabas Medical Center, 94 Old Short

Hills Road, Livingston, NJ 07039, USA

Tel + I 9733225195

Fax + I 973322 247I

Email rchamberlain@barnabashealth.org

\section{Dear editor}

We appreciate the editorial comments and suggestions by McFarland included here, as well as the ability to respond to their critique. This author makes several valid points about the type of data, which is clearly needed to better understand the impact of specific probiotics on Clostridium difficle-associated diarrhea (CDAD) prevention. The previously published meta-analysis entitled "Probiotics are effective at preventing Clostridium difficile-associated diarrhea: a systematic review and meta-analysis" was performed to evaluate the impact of probiotics on CDAD. ${ }^{1}$ Given existing data, the only means to answer this question via meta-analysis required that all existing data be pooled. That said, we also conducted a subgroup analysis based on the genus of probiotic, to determine which probiotic genus (Lactobacillus, Bifidobacterium, and Saccharomyces) were most beneficial at preventing CDAD. The category "mixture of probiotics" included strains from more than one probiotic genus. As suggested by McFarland in their editorial, additional more detailed subgroup analysis based on unique probiotic species would be ideal; however, given the variation in specific species utilized in published reports, the paucity of published randomized control trials (RCTs) evaluating each species, and the fact that the vast majority of all published RCTs included a combination of different probiotic species, a subgroup analysis by probiotic species was not possible.

As mentioned in the "Discussion" section, there are limitations to our published report, as well as limitations that are inherent to meta-analyses in general. The specific strains, dosages, and duration of probiotic regimen differed widely. Ideally, the best way to determine the optimal probiotic regimen would be to conduct RCTs comparing specific strains and dosages of probiotics. Given the limited availability of such data, the next-best method is the use of a subgroup analysis. The original article demonstrated the effectiveness of probiotics in reducing the risk of CDAD, and a subgroup analysis identified different efficacies based on probiotic genus. ${ }^{1}$ More recently, McFarland reported that there were efficacy differences based on specific species - and that $S$. boulardii, BioK+ mixture, a mixture of three Lactobacilli strains, and a mixture of L. acidophilus plus B. bifidum are beneficial at reducing the risk of $\mathrm{CDAD}$, while $L$. rhamnosus GG does not significantly reduce the risk of CDAD.

\section{Disclosure}

The authors report no conflicts of interest in this communication.

\section{Reference}

1. Lau CS, Chamberlain RS. Probiotics are effective at preventing Clostridium difficile-associated diarrhea: a systematic review and meta-analysis. Int J Gen Med 2016;9:27-37.

Dove Medical Press encourages responsible, free and frank academic debate. The content of the International Journal of General Medicine 'letters to the editor' section does not necessarily represent the views of Dove Medical Press, its officers, agents, employees, related entities or the International Journal of General Medicine editors. While all reasonable steps have been taken to confirm the content of each letter, Dove Medical Press accepts no liability in respect of the content of any letter, nor is it responsible for the content and accuracy of any letter to the editor.

\section{Publish your work in this journal}

The International Journal of General Medicine is an international, peer-reviewed open-access journal that focuses on general and internal medicine, pathogenesis, epidemiology, diagnosis, monitoring and treatment protocols. The journal is characterized by the rapid reporting of reviews, original research and clinical studies across all disease areas.
The manuscript management system is completely online and includes a very quick and fair peer-review system, which is all easy to use. Visit http://www.dovepress.com/testimonials.php to read real quotes from published authors. 